\title{
LOS MUNDOS DE LUISA MERCEDES LEVINSON, CUENTISTA
}

El cuento hispanoamericano está representado de una manera excepcional en la persona de Luisa Mercedes Levinson, de Argentina. Levinson, que figura en importantes antologías internacionales, se destaca en el mundo literario de todo el continente como autora que sabe combinar en un conjunto armónico y original los elementos más diversos y a veces contrarios. Maneja con facilidad el mundo fantástico, la introspección y el realismo dramático. Se entrelazan de un modo calidoscópico lo prosaico de cada día con lo raro y lo exótico, lo estático con lo efímero. Sus personajes pueden ser dibujados nítidamente o sólo sugeridos de una manera fugaz. El mundo de Levinson es poblado por lo sensual y lo violento, así como por lo angélico y lo etéreo. La autora prefiere y sobresale en la caracterización de personajes femeninos. La presencia de personajes masculinos sirve sólo para hacer resaltar aquéllos. A fin de ilustrar esta tendencia hemos escogido algunos cuentos, los cuales - lejos de constituir una vista general- no son más que muestras de la obra polifacética de la autora.

Comencemos con el primer ejemplo. En «Miedo a Valparaíso» ${ }^{1}$ nos encontramos con la polarización sueño-realidad, uno de los temas predilectos de Levinson. Para resumir brevemente: dos novios van de vacaciones a Viña del Mar. Marina anticipa y realiza un amor loco y desenfrenado antes de casarse. Pasada esta temporada, los dos amantes se casan y regresan a Buenos Aires. Ha terminado la época del placer promiscuo y empieza la vida respetable y monótona. Al bajar un día en el ascensor, Marina tropieza con un joven que se dirige a ella llamándola Maritza. Simbólicamente, Maritza representa el sueño de Marina, el de la emancipación de todos sus deseos reprimidos. Maritza se escapa con el joven a Valparaíso, "el Valparaíso perdido», y lleva allá una vida muy

1 "Miedo a Valparaíso», en L. M. Levinson, Las tejedoras sin hombre (Buenos Aires: Ed. Losada, 3. ${ }^{a}$ ed., 1968), pp. 125-132. 
alegre, hasta tal grado que se pierde en un barrio de prostitutas. Es arrestada porque por ella ha muerto el hombre con quien ha pasado la noche. Principio del fin. Ahora la dualidad Marina-Maritza, dentro de la cárcel, se transforma en María, símbolo de un mejor mundo, mundo que reemplaza el mundo perdido, como lo es Valparaíso. Porque es María la que mira a través de la claraboya, más arriba de la ventana tapiada, y tiene una visión de la ciudad nueva, ciudad luminosa y sagrada. Pero los otros presos no comparten esta visión. Los que se niegan a aceptarla quieren lincharla. El visionario, el idealista, siempre ha corrido este peligro. Irónicamente, al final del cuento llegan los carabineros y tapian la claraboya; ahora ya no hay posibilidades de visiones. De manera que tenemos aquí un juego dialéctico, expresado por varios momentos sucesivos en la vida de Marina-Maritza-María: El entregarse del individuo al mundo de los placeres y deseos, seguido de la vida convencional y gobernada por limitaciones, la cual produce a su vez una reacción, a saber: el escape de nuevo al mundo de los apetitos desenfrenados, y, finalmente, la antítesis, o sea, el rechazo de esta manera de vivir en forma de una visión de un mundo idealizado, pero una visión destrozada cínica y trágicamente por los guardianes de la realidad brutal.

El tema, amor-muerte o violencia-amor, el enlace íntimo entre los dos, aparece en «La muchacha de los guantes» ${ }^{2}$. Carlos, profesor de Buenos Aires, ha sido invitado a Alemania para dictar una serie de conferencias sobre la literatura hispanoamericana. Aquí establece una relación amistosa con Herta, una de sus estudiantes, la cual siempre 1leva guantes para cubrirse las manos - manos deformadas, sospechamos, en un campo de concentración-. Carlos está casado con una mujer paralítica, pero a pesar de eso le ha permanecido fiel. La muchacha, Herta, se siente atraída hacia el profesor, y además siempre ha querido viajar y vivir en un país lleno de sol. Y al profesor, dicho sea de paso, le gusta acariciar las manos de su estudiante... Terminado el ciclo de conferencias, Carlos se despide de Herta y regresa a Buenos Aires para cuidar a su mujer. Herta le sigue poco después; no puede estar sin él. Se dirige a la casa del profesor; en ella sólo se halla la esposa. Herta entra, se acerca cautelosamente a la silla donde está sentada la paralítica, se quita los guantes y, con manos monstruosas, la mata. Nos enfrentamos aquí, claro está, con un caso de frustración en un aspecto triple: frustración del marido, que no puede llevar una vida normal en el pleno sentido de la palabra; la esposa, quien no hace más que esperar la muerte, y la última, la de Herta misma, cuyo amor reprimido termina con la muerte, por medio

${ }^{2}$ «La muchacha de los guantes», en Las tejedoras..., pp. 60-72. 
de la cual quedan destruidas a la vez las tres frustraciones. El poder descriptivo de Levinson es innegable; a veces resultan efectos grotescos, como, por ejemplo, cuando Herta está a punto de matar: "Y esas manos adoptaron su posición natural de garras y apretaban el cuello macilento un poco más arriba de la jorobita de grasa...» (p. 72).

Del siguiente cuento, «Más allá del Gran Cañón» ${ }^{3}$, sacamos la moraleja: Todos tenemos que participar del amor, sea cual fuere nuestra condición social. Se trata aquí de una pareja: un negro esclavo y una blanca prostituta sureña de los Estados Unidos. A ella la han echado de un prostíbulo por ser víctima de la viruela negra. En un sentido irónico, el prostíbulo será símbolo de la raza blanca. Por eso, la mujer se encuentra ahora en una condición aún peor, $i$. e., tiene que quedarse con un negro. De día trabaja él, y ella es la que manda con el látigo en la mano. De noche son amantes. Pero cuando los dos se enteran de que ya no hay ricos ni esclavos en el país, la relación se vuelve a la inversa, en un desenlace irónico: ahora trabaja ella, el negro es el que manda. Antes había bailado ella, ahora baila él.

«La pálida Rosa de Soho» "trata del mundo británico del «country club» snobista y de su antítesis, el barrio del bajo mundo de Londres. Lo artístico en la obra de Levinson queda bien ejemplificado en la habilidad de la autora de contraponer un retrato, pintado en un lenguaje lírico y musical, contra un trasfondo sórdidamente realista. Las imágenes que utiliza ella intrigan y encantan. Pálida Rosa, la más atractiva y más costosa de las mujeres de la calle, deja sin aliento a los turistas por la ondulación de su rítmico andar. «Si bien no descolló en el arte musical, es capaz de triunfos de otra índole» (p. 11), lo cual revela el humor pícaro del cual es maestra la autora.

Pálida Rosa está enamorada del joven Whippety Dick, violinista que toca en Picadilly Circus. Las mujeres de mediana edad que vuelven a casa todos los días después de haber hecho sus compras siempre le echan una mirada de ternura y compasión. De noche los dos amantes hablan de los viajes que van a hacer con el dinero que han reunido en el transcurso del día. Pero estos sueños no están destinados a realizarse. El señor Norman Murchison Jr., del mundo de los «Garden Clubs», tropieza con Pálida Rosa durante una de sus visitas al barrio Soho. Vuelve a visitarla repetidas veces. Para ella, el señor Murchison es símbolo de un mundo inaccesible, pero, sin embargo, sueña con utilizarlo para escapar del suyo. Mientras tanto, Whippety Dick empieza a emborracharse cada vez más

3 "Más allá del Gran Cañón», en Las tejedoras..., pp. 115-123.

‘ La pálida rosa de Soho (Buenos Aires: Ed. Losada, 1967), pp. 9-20. 
-ya sospechamos por qué-, y un día Pálida Rosa aparece ahogada en el río Támesis: otro ejemplo de la fórmula amor-muerte. Se descubre también en el río el violín de Whippety Dick y, claro, como resultado queda éste encarcelado. E1 último toque irónico es típico de Levinson. Las mujeres de Picadilly Circus, que siempre escuchaban la música, le comprarán otro violín para que pueda seguir tocando en la cárcel. Y los miembros del jurado que van a condenarlo visitarán el mismo barrio de Soho para buscar a las compañeras de Pálida Rosa.

"La isla» ${ }^{5}$ es otro ejemplo del talento de Levinson para combinar lo lírico con lo trágico. Este último adquiere cada vez más fuerza a medida que llega el lector al final del cuento. La bella Eurídice, o Euri, ha recibido como regalo un loro, que desgraciadamente le ha picoteado la pierna. Poco después aparecen algunas manchas sospechosas, las que -cree Jorge- son una indicación de lepra. Euri, convencida de que en verdad ha caído víctima de esta enfermedad, escapa a una isla de leprosos. Jorge la sigue para quedarse con ella. Los dos estarán «cercados por el amor, como la isla estaba cercada por el río» (p. 59). Pero Euri está dispuesta a ser más que víctima. Quiere ayudar y servir. Organiza sesiones de lectura para los leprosos; éstos van enamorándose de ella con una devoción fanática. En cambio, a Jorge le repugnan los habitantes de la colonia y decide dejar la isla con su amada. Como resultado, los leprosos se sublevan contra él y lo atacan. Euri también, en un momento crítico, le echa un puñado de barro, obligándole a escapar. De ahora en adelante ya no mirará ella el río; para ella no existe nada más que la isla. El contraste entre el río y la isla, representado por Jorge y Euri respectivamente, se desarrolla con un ritmo cada vez más acelerado. Tarde o temprano los dos tendrán que separarse. De noche, la isla parece bellísima con sus aromas de flores blancas. Pero con el amanecer aparecen otra vez las miserias. El sonar de las pulseras de plata que lleva Euri se repite periódicamente a través de la obra como un presagio de lo inevitable del desenlace final, a la manera de Edgar Allan Poe.

«El abra» ${ }^{6}$ nos hace pensar no sólo en Poe, sino también en Horacio Quiroga y José Eustasio Rivera. Es un cuento de pasión y venganza ubicado en un ambiente rural, pero, sin embargo, teñido de fuertes matices líricos. El ambiente selvático sugiere en seguida una atmósfera 1lena de calor y sensualidad. El centro de la acción es una hamaca, y el protagonista principal, una mujer. Ella ha sido traída al abra por su patrón, don Alcibíades, sacada del prostíbulo para satisfacer las necesidades bio-

\footnotetext{
«La isla», en La pálida rosa..., pp. 53-59.

" «El abra», en La pálida rosa..., pp. 31-39.
} 
lógicas del macho. Se siente engañada porque el patrón la ha decepcionado; le había prometido mucho, pero sin haber cumplido. El tercer personaje, el Ciro, es un joven adolescente que trabaja como peón. En la primera escena, la mujer aparece tendida en la hamaca y se queda allí hasta el final del cuento. La técnica de Levinson en este caso - sobre todo su empleo de imágenes sugestivas - resulta en un erotismo sutil. El patrón anuncia que se va a la ciudad. Cuando ya se ha marchado, la mujer decide vengarse de él iniciando un juego felino para atraer al joven. «Ella se desperezó, después se desprendió la blusa, como si la botonadura le lastimara el pecho... Su rostro permanecía impasible; sólo el cuerpo, en ondulaciones sobre la red..., se multiplicaba en su aleteo...» (p. 33). Ocurre lo que tiene que suceder. Ciro es una víctima bien dispuesta. Pero ha caído en la trampa. De repente aparece otra vez el patrón, saca su revólver y lo mata. Luego toma los bordes de la hamaca y la cierra sobre la mujer, trenzándola con el lazo. La soga va cerrándose sobre la cara y a lo largo del cuerpo. El suplicio será monstruoso: primero, los rayos del sol, y luego las hormigas. Pero ella, sin que él lo sepa, tiene guardado un revólver en la falda. Suena un tiro y cae don Alcibíades. Ella hubiera podido salvarse utilizando sus poderes tentadores de mujer, pero decide matarlo sin más ni más. Tanto lo odia. Y al hacerlo, mata también todas las posibilidades de su propio futuro -posibilidades perdidas porque ya no espera nada de la vida-. Otra vez se enfrenta el lector con el enlace entre el amor y la muerte. $Y$ en medio de esta escena grotesca - dos muertos que yacen debajo de la hamaca- desfilan las alucinaciones y los flashbacks de la agonizante: «Sombras, graznidos, alas pegajosas, le abofetean la cara, le picotean los muslos y las caderas, la salpican de negrura y de muerte» (pp. 38-39).

«En un cuaderno cuadriculado» ${ }^{7}$ es un cuento patético, escrito en forma autobiográfica por una jovencita, María, que nació con un hombro más alto que el otro - y eso porque a su madre «le dio mi padre una patada en el vientre antes de mi nacimiento» (p. 89)—. Pero la joroba no impide que se enamore locamente del muy guapo Mario del Río, «el más alto, el más dulce, el que daba más miedo» (p. 89). En cambio, Mario no tiene la menor idea de los sentimientos de la muchacha. Su único contacto con ella se limita al momento en el cual pone la mano en el hombro abultado, diciendo: «Muy pronto te crecerá el ala; para ese tiempo, espérame» (p. 90), lo que nos hace pensar en aquella alegoría tan lírica y hermosa, Alsino, del chileno Pedro Prado.

Mario del Río se casa con Lolita, y casi inmediatamente después

7 «En un cuaderno cuadriculado», en La pálida rosa..., pp. 89-97. 
ella lo traiciona. Los primos de Mario deciden castigar esa infidelidad $y$, acompañados de Mario, van en tren a la casa donde se encuentran Lolita y su amante. Pero sin que nadie se dé cuenta, la jorobadita se ha escondido en el tren, porque tiene el presentimiento de que algo desagradable puede pasarle a Mario. Al llegar al lugar donde está Lolita, los primos se preparan a «limpiar la mancha» y salvar el honor de la familia. Pero Mario ya ha perdido el deseo de vengarse, sobre todo cuando ve que sus primos llevan revólveres. Se escapa en un coche junto con María. Los primos, rabiosos, tiran contra el coche y la pobre María recibe una bala en la joroba. Ella mantiene un silencio estoico a pesar de que la bala es fatal. Claro que Mario no sabe nada porque no ve que bajo el saco de ella corre «un hilo delgado, un río pequeño» (p. 95). En la última escena, Levinson nos ofrece una fusión de realidad y fantasía. A la noche, María ya está muriendo; «cuando los trenes del cielo se entrecruzan» (p. 97), ella sigue hablando: "Y siento algo tibio y liviano sobre la herida, algo que se extiende y se echa a volar. No, no puede ser el ala, claro que no. Es la mano de Mario del Río que viene a decirme adiós» (p. 97). María ha alcanzado lo inalcanzable.

También el cuentecito de menos de tres páginas, «El sueño violado" ${ }^{8}$, nos demuestra que Levinson se siente a sus anchas en el mundo fantástico. Elsa Grau, la única protagonista, se encuentra en un cine mirando una película en donde un hombre y una mujer utilizan el mismo catre para dormir. Cuando él trabaja, duerme ella, y viceversa. Este uso alternativo del catre, sin cesar, debe resultar - así piensa Elsa- en un sueño continuo sin pausa. En otras palabras: el sueño se sirve de los dos para perpetuarse. Elsa se siente atrapada como si fuera participante activa dentro del sueño; da un paso hacia adelante, tiene la impresión de que las figuras del sueño la están llamando. Precisamente en este momento deja su mundo físico y pasa al otro lado del espejo, por decirlo así, para penetrar en el mundo del sueñc. Ahora se siente apresada y aterrada; no puede salir del círculo, símbolo del sueño. Se da cuenta de que, si el hombre se despierta, será urgente que alguien lo releve y que siga durmiendo este otro individuo. Y Luisa Mercedes Levinson, con su sentido de humor siempre tan encantador, termina su fantasía, dirigiéndose al lector mismo: «Continúe usted el sueño, por favor. Piense que esto de violar un sueño es algo que podría pasarle a cualquiera, hasta a usted» (p. 136).

En «La niña Panchita» ${ }^{9}$, el narrador relata en primera persona los

\footnotetext{
8 «E1 sueño violado», en La pálida rosa..., pp. 134-136.

${ }^{9}$ "La niña Panchita», en La pálida rosa..., pp. 70-76.
} 
sucesos que terminan en un doble asesinato - resultado de un amor no correspondido, ambiciones frustradas, relaciones sociables conflictivas-, todo lo cual lleva al lector al desenlace inevitable, que aquí es el castigo. La niña Panchita, una belleza con «ojos de carbón» (p. 71) y otros tesoros indescriptibles, llega a la estancia de don Marcelino Zaldarriaga. Don Marcelino, ya entrado en años, tiene por la niña «un cariño paternal, y algunos dicen que algo más» (p. 71). La niña resulta fatal para el domador del rancho, Abelardo Socas. Este ha pensado cortejarla, y una noche, mientras se acerca a la casa, los perros de la estancia lo atacan y lo matan. Don Marcelino descubre un día que no puede mover los brazos; se ha quedado tieso y torcido. No pudiendo soportar esta parálisis, se suicida, y la niña Panchita llega a ser la patrona de la estancia. Ahora es cuando aparece en el escenario el pobre gaucho que antes había desaparecido del rancho. Sólo que esta vez - ya han pasado seis meses - ha regresado con mucha plata, bastante para comprar la hacienda. Eleuterio Fernández — así se llama- está perdidamente enamorado de la niña Panchita - algo que se ha sospechado desde el principio-. En una escena patética le ofrece todo lo que tiene, pero ella lo rechaza; lo considera socialmente inferior. La culminación se alcanza en la última escena. El narrador, caminando por la selva, descubre el cuerpo desnudo de Panchita, quien acaba de recibir una puñalada mortal de Fernández. El narrador, a su vez, saca su facón y le da muerte al asesino. Aquí termina el cuento, y nos damos cuenta de que el narrador ha sido arrestado y está contando esta serie de episodios al señor juez.

Levinson tiene el don de utilizar colores para crear efectos sensuales. Por ejemplo, el narrador, al observar a Panchita, dice: «... casi podía oler la negrura de su pelo» (p. 74). Los ojos de Panchita son «renegridos» y parecen "rejuntar todas las penas de los campos y los poblados» (p. 73). Hace pensar en aquella limeñita, Margarita, de Ricardo Palma, que «lucía un par de ojos negros que eran como dos torpedos con dinamita...» ${ }^{10}$. El narrador se acuerda de la niña Panchita «y su sombra como un gran murciélago en la pared...» (p. 72). El color blanco aparece dramáticamente como fuerte contraste: «Blanca debe ser la mujer... para aclarar el alma del varón...» (p. 73). En la última escena se patentiza el contraste entre «la espalda blanca» de Panchita y la «sombra» de Fernández «como un tronco de árbol largo, oscuro» (p. 75). El narrador entierra a Panchita porque «la tierra cubre la blancura y cubre bien» (p. 75).

10 «La camisa de Margarita», en Ricardo Palma, Tradiciones peruanas (Buenos Aires: Espasa-Calpe, 2." ed., 1943), p. 37. 
Una nota algo caprichosa, adornada de una suave ironía y matizada con detalles líricos, es realizada de una manera magistral en «Los dos hermanos» "1. La rubia, Frida Klager, diva wagneriana, de ojos nórdicos, ha regresado a la Argentina después de haber pasado más de dos décadas en Europa. Ha sido invitada a hospedarse en un predio de Misiones, debidamente nombrado «el Walhala», el que pertenece a su hermano Otto. Se sospecha que entre los dos «arianos» existe una relación, la cual es algo más que un parentesco simple e innocuo entre hermanos. Es precisamente por eso, para poner fin a las murmuraciones, que Otto decide casarse con la chinita Encarna, la criada de la casa. Protegidos por este ardid, siguen como antes las relaciones entre los dos hermanos. Después de todo, iFrida tiene carne blanca!

Para mantener este equilibrio algo inestable, Frida le regala a Encarna blusas, enaguas, perfumes y otras prendas por el estilo. Encarna sigue llevándole el desayuno todos los días; mientras tanto sueña con Rosendo, de quien estaba enamorada cuando vivía al otro lado del río, sumergida en la miseria. Y claro, los dos tienen que encontrarse otra vez, pero de una manera inesperada. Una noche, Rosendo, con unos compañeros suyos, entran en la estancia y se vengan del patrón. Muerto Otto, los peones quieren violar a Frida. Pero Encarna ya sabe apreciar la diferencia entre una vida relativamente cómoda y la del pantano de la otra orilla. No le importa la muerte de Otto. Pero Frida, iésta es harina de otro costal! A ésta la necesita: le gustan las blusas de seda verde, porque «así me nacen flores en los pechos...» (p. 45). Y Encarna les contesta que la patrona no está. La turba abandona la casa y Encarna sube al dormitorio para despertar a Frida, la cual parece haberse desmayado. Y desde aquel día en adelante Encarna sigue sirviéndole la comida. La autora termina el relato de una manera preciosa, la que recuerda el estilo de O. Henry: Frida «se envejece dignamente, mientras en el secadero, año tras año, va mejorando la calidad de las hojas del té» (p. 47).

«E1 doctor Sotiropoulos» ${ }^{12}$ nos mete dentro de un ambiente empapado de un aire de misterio. Es un cuento narrado por una señora que está de viaje a bordo de un yate. Está hablando a otro pasajero, profesor de psicología, a quien le llama la atención el título del libro que está leyendo la señora: Dr. Jekyll and Mr. Hyde. El relato trata de un episodio que ella había vivido cuando era jovencita, unas dos décadas atrás. La técnica de Levinson capta de inmediato el interés vital del lector, quien se

11 "Los dos hermanos», en La pálida rosa..., pp. 40-47.

12 «El doctor Sotiropoulos», en J. L. Borges y L. M. Levinson, La hermana de Eloísa (Buenos Aires: Emecé Editorial, 1955), pp. 23-36. 
siente colocado dentro del ambiente misterioso y enredado en el argumento que hilvana la pasajera. Esta habla en primera persona, utilizando al mismo tiempo mucho diálogo, y todo esto dentro del marco de dos realidades: la presente y la pasada.

Si una personalidad puede dividirse - pregunta la señora so pretexto de entablar una conversación-, como es el caso con los dos personajes de Stevenson, ¿es posible también que un alma pueda usurpar el lugar de otra, dentro del mismo cuerpo? La pregunta trae a la memoria la vieja leyenda judía que se encuentra en el Dybbuk, y también el tema más reciente y sensacional del «best seller» El exorcista. Sin que el psicólogo le pueda contestar, la mujer le señala un viejo castillo, que aparece a lo lejos en la orilla del mar. Fue allí donde hacía muchos años ella y su madre habían explorado las ruinas, mientras su padre y su novio estaban pescando, alejados unos cuantos kilómetros. El castillo, sigue hablando la señora, rememoraba los castillos de Poe, con su atmósfera sombría, producto típico de la novela gótica. Las dos mujeres, solas, oían acercarse de repente una lancha a motor. Completamente aisladas, intentaron escapar, pero se dieron cuenta de que sus caballos no estaban allí donde los habían dejado. Apareció en ese momento el doctor Sotiropoulos, con sus ojos «de un verde fosforescente, como los de algún animal..." (p. 29). En el mismo momento pasaba misteriosamente por encima de las dos mujeres una manada de garzas, dejando atrás un remolino de plumas, dos de las cuales llegaron a descansar una en cada hombro del doctor Sotiropoulos. Las garzas de Levinson y el cuervo de Poe, ¿representaban algo más que pura coincidencia? ¿Habían desaparecido los caballos también por casualidad? El doctor Sotiropoulos le atraía y le causaba repulsa al mismo tiempo; la pasajera está ahora hablando con una celeridad febril. Invitó a las dos mujeres a pasar la noche en el castillo, pues era bastante tarde. La joven se sentía abrumada por los poderes hipnóticos del doctor. Este hablaba de que había hecho investigaciones parapsicológicas y que había logrado «la liberación parcial de las almas» (p. 31). Levinson ya ha reemplazado la realidad por la fantasía; y no sólo las dos mujeres, sino también el lector, han sucumbido víctimas del ambiente espectral. Estaba a punto de desmayarse, sigue hablando la señora. Recuerda que llamaba con desesperación a Juancito, su novio. Admite que se presta fácilmente a ser sugestionada. Esto no tiene sentido, le dice al psicólogo, no puede explicarse racionalmente. Pero existen otras explicaciones, insiste, y quiere saber al final de la narración si su alma es la misma todavía después de tantos años. Y deja de hablar. Un año más tarde, el profesor regresa al mismo lugar, es decir, a la montaña, y se encuentra con Juancito. Le pregunta dónde está la 
mujer que le había contado la aventura. Juancito le contesta que ella ha desaparecido, que ya no viven juntos. $Y$ mientras los dos hombres están charlando, va cayendo la pluma de una garza hasta descansar en el hombro del psicólogo. Todavía la tiene.

Es evidente que Levinson puede crear por medio de la sugestión y retener hasta el último momento un ambiente irreal, casi mágico, que fácilmente termina como la única realidad posible para el lector.

"Edayeh o la sustitución de la sustitución»" ${ }^{13}$ nos demuestra que Levinson puede navegar en el mar de la ciencia-ficción y que el frío científico, razonador e impersonal, es capaz también de tener apetitos e instintos vitales, sobre todo cuando se trata de una linda mujer.

El viejo investigador, G-1, relata a su alumno, G-2, también científico respetado, sus aventuras amorosas. Después de haber pasado tanto tiempo en el laboratorio, se le suelta la lengua con la ayuda de un vaso de whisky, y confiesa que está enamorado de una de sus discípulas. Además - y esto es el colmo - ella le ha exigido «una cita en la intimidad» (p. 16).

Parece que el profesor G-1 tiene un exceso de confianza en su colega. Lo considera, después de casi dos décadas, como una especie de alter ego, extensión o continuación de sí mismo. Quiere realizarse a través del joven. Por eso le pide ahora a su colega que lo sustituya, que acuda él a la cita nocturna y que se consume el hecho en la oscuridad. G-2 será el medio, y él, G-1, modestamente, el fin, este mismo G-1, cuyas teorías sobre el amor están basadas en explicaciones puramente científicas. Pero al final de la narración el lector se da cuenta de que esta propuesta algo rara se ha vuelto aún más grotesca al descubrir que se ha efectuado una doble sustitución: la muchacha ha mandado a una compañera para reemplazarla. El lector no sólo se queda perplejo por lo inesperado del argumento; también es muy impresionante la facilidad con la cual maneja Levinson la jerga supuestamente científica. Parece que la única verdad básica que la autora quiere subrayar estriba en el conflicto perenne entre el hombre que piensa y el que siente.

Para terminar, Luisa Mercedes Levinson nos ha mostrado que puede combinar de una manera cabal lo estético y lo social, el vigor nativista con la elegancia cosmopolita, el lirismo con el realismo brutal. $\mathrm{Ha}$ sabido penetrar en la psicología de la naturaleza humana para revelar lo trágico, lo patético, lo absurdo. En todos sus cuentos, Levinson da muestras de una rica variedad de técnicas literarias: una mezcla de diálogo con la narración en la primera y tercera personas; de tiempos distintos

${ }^{13}$ «Edayeh o la sustitución de la sustitución», en Las tejedoras..., pp. 13-23. 
- a veces en el mismo párrafo- para representar varios puntos de vista, varias perspectivas; sueños, monólogos, efectos mágicos y reminiscencias, para indicar realidades múltiples. La autora no deja nada al azar; todo está en su lugar, a pesar de que con su increíble poder imaginativo puede saltar a veces por encima de las categorías espacial y temporal. El lector, una vez que entra en el mundo fascinante de Luisa Mercedes Levinson, no quiere dejarlo.

McGill University, Montreal, Canadá

SOLOMON LIPP 
